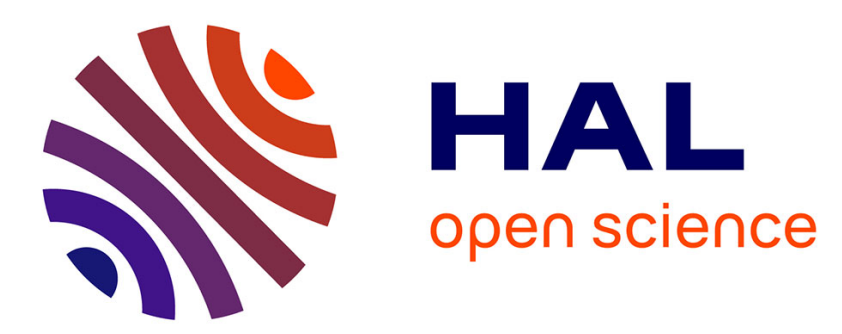

\title{
The Sensitivity of Abradable Coating Residual Stresses to Varying Material Properties
}

\author{
Richard E Johnston
}

\section{To cite this version:}

Richard E Johnston. The Sensitivity of Abradable Coating Residual Stresses to Varying Material Properties. Journal of Thermal Spray Technology, 2009, 18, pp.1004 - 1013. 10.1007/s11666-0099378-2 . hal-01430524

\section{HAL Id: hal-01430524 https://hal.science/hal-01430524}

Submitted on 10 Jan 2017

HAL is a multi-disciplinary open access archive for the deposit and dissemination of scientific research documents, whether they are published or not. The documents may come from teaching and research institutions in France or abroad, or from public or private research centers.
L'archive ouverte pluridisciplinaire HAL, est destinée au dépôt et à la diffusion de documents scientifiques de niveau recherche, publiés ou non, émanant des établissements d'enseignement et de recherche français ou étrangers, des laboratoires publics ou privés. 


\title{
The Sensitivity of Abradable Coating Residual Stresses to Varying Material Properties
}

\author{
R.E. Johnston
}

\begin{abstract}
This paper reports recent research on abradable materials employed for aero-engine applications. Such thermal spray coatings are used extensively within the gas turbine, applied to the inner surface of compressor and turbine shroud sections, coating the periphery of the blade rotation path. The function of an abradable seal is to wear preferentially when rotating blades come into contact with it, while minimizing over-tip clearance and improving the efficiency of the engine. Thermal spraying of an abradable coating onto a substrate imparts two components of residual stress; rapid quenching stresses as the spray material cools on impact and stresses arising from differential thermal contraction. In-service thermal stresses are superimposed by the differential expansion of these bonded layers. The combination of the production and operation history will lead to thermal-mechanical fatigue damage within the abradable coating. The present paper will describe the numerical modeling and sensitivity analysis of the thermal spray process. The sensitivity of residual stresses (with varying material properties, coating/substrate thickness, Poisson's ratio, and substrate temperature) predicted by the Tsui and Clyne progressive deposition model enabled identification of performance drivers to coating integrity. Selecting material properties that minimize in-service stresses is a crucial stage in advancing future abradable performance.
\end{abstract}

Keywords applications, APS coatings, coatings for gas turbine components, coating-substrate interaction, modeling, properties, spray deposition

\section{Introduction}

Plasma spraying of coatings onto a suitable substrate falls under the umbrella of thermal spray processing. In the production of gas turbines, plasma spraying is used to manufacture abradable seals around the circumference of the compressor and turbine blade sections. The abradable seal lies along the periphery of the blade rotation path, providing reduced clearance between the rotating blade tip and stationary engine casing (termed over-tip clearance). The clearance is minimized because the abradable coating is installed and wears preferentially to the blade tip. Blades cut into the abradable as it sweeps a path during rotation, producing a rub track where the blade tips rotate while seated within a groove in the abradable coating. Reducing the over-tip clearance can lead to significant improvements in the efficiency of the engine and specific fuel consumption (SFC) (Ref 1) because more gas is drawn through the blade area and less escapes over the tips of the blades, therefore imparting more work to blade rotation.

R.E. Johnston, Materials Research Centre, School of Engineering, Swansea University, Singleton Park, Swansea SA2 8PP, UK. Contact e-mail: r.johnston@swansea.ac.uk.
A plasma flame is used to rapidly heat the abradable powder, which is accelerated at high velocity onto the surface of the substrate. The coating is formed in layers with successive passes of the plasma spray gun. A coating powder material consisting of an AlSi matrix and hexagonal boron nitride ( $\mathrm{hBN}$ ) dislocator phase (Metco 320NS), a bond coat of composition $96 \% \mathrm{Ni} 5 \% \mathrm{Al}$ (Metco 450NS), and substrate material Jethete M152 (RR EAK) were considered for this study.

Residual stresses are generated in coatings during their manufacture. Thermal spraying of a coating onto a substrate imparts two components of residual stress. The first component is introduced as the molten or thermally softened coating powder impacts with the surface of the substrate or previously deposited coating layer, which is at a lower temperature, forming a 'splat'. These particles are flattened and quenched to the underlying surface temperature with very high cooling rates, typically in excess of $10^{6} \mathrm{~K} / \mathrm{s}$ (Ref 2). During this rapid cooling, the thermal contraction of the splat will be constrained by the underlying material, therefore introducing a tensile stress into the sprayed material.

The second component of residual stress is due to differential thermal contraction during cooling of the sprayed coating and substrate part to room temperature. Stresses are induced when bonded layer materials having different coefficients of thermal expansion, cool and contract at different rates. Normally, the coating will have a greater coefficient of thermal expansion than the substrate and will therefore experience greater contraction upon cooling, and subsequently an induced tensile stress. 
Stoney (Ref 3) derived an equation to predict residual stresses in thin films (film thickness $\ll$ substrate thickness). The first analytical model for elastic thermal stresses in a bilayer system was derived by Timoshenko (Ref 4), and was based on classical bending theory. This approach has been widely adopted to analyze thermal stress in multilayer systems (Ref 5-7). Closed-form solutions considering metal/ceramic bonded strips have been derived for elastic loadings $(\operatorname{Ref} 8,9)$ and for the elastic/plastic state, incorporating work hardening into the metallic layer (Ref 5). These models consider only the residual stresses due to differential thermal expansion/contraction of bonded multilayer systems.

Models have been developed that incorporate both the stresses derived from differential thermal contraction, and the 'quenching' stresses developed during the thermal spray deposition process. Tsui and Clyne (Ref 10) developed an analytical model for prediction of residual stress distributions in progressively deposited coatings. This paper investigated the effect on predicted residual stress distributions of changing various material properties and deposition parameters. The aim of this work was to devise, for abradable coating materials, a tool that will aid future coating design decisions, based on minimizing the postproduction residual stresses. The Tsui and Clyne deposition and contraction model architecture is well suited to a sensitivity study of input parameters, and the processes modeled are the equivalent of those used to produce abradable coatings.

\section{Tsui and Clyne Progressively Deposited Coatings Analytical Model}

Tsui and Clyne (Ref 10) formulated a model, based on planar geometry, to predict residual stresses introduced to a substrate and coating during deposition and also during cooling of the sprayed coating/substrate. The model assumes that the substrate is clamped only at one end, while being free to bend during the process, as shown in Fig. 1 .

The full derivation of formulae and nomenclature can be found in Tsui and Clyne's paper entitled 'An Analytical Model for Predicting Residual Stresses in Progressively Deposited Coatings. Part 1: Planar Geometry' (Ref 10).

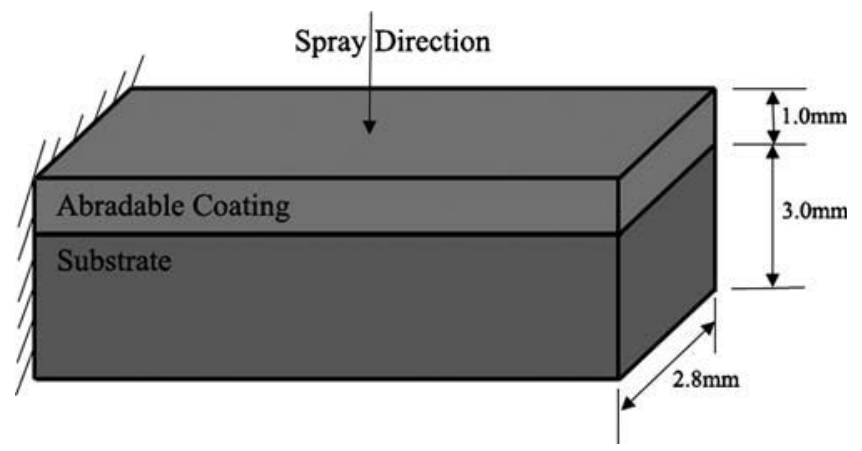

Fig. 1 Tsui and Clyne beam configuration
The Tsui and Clyne model was selected for several reasons. Firstly, its suitability for a sensitivity study, and secondly, it does not require consideration of complex heat transfer mechanisms, inelastic material behavior and temperature dependence. Abradable material properties in freestanding form are relatively unknown. Only in recent years have methods (Ref 11) been developed for investigating these properties without the associated substrate interactions. Until these properties have been fully investigated, the Tsui and Clyne model is the most suitable method for performing a sensitivity analysis of abradable coating materials.

\section{Modifications to Tsui and Clyne's Model}

Several modifications were made to the Tsui and Clyne progressively deposited coatings analytical model to produce a model that mimics abradable coating production processes as closely as possible:

Firstly, Tsui and Clyne's model uses one value for $\Delta T$ throughout the chain of calculations. The modified model uses a value of $\Delta T\left(\Delta T_{\mathrm{dep}}\right)$ during the deposition stress calculation and a separate $\Delta T\left(\Delta T_{\text {cool }}\right)$ value during the cooling stress calculation. A bond coat is applied to the substrate to assist adherence of coating (keying). An example of Metco 320NS abradable coating applied to a Metco 450NS bond coat and Jethete Steel substrate is shown in Fig. 2.

The bond coat (Metco 450NS) was included in the model as the first tier in the discretized coating layer. The coating was divided into ten layers previously for the model; this model utilizes the first layer for bond coat material and remaining nine layers are abradable coating material. The bond coat was not discretized into more than one layer as the calculation of the associated residual stress distribution was deemed unnecessary, particularly

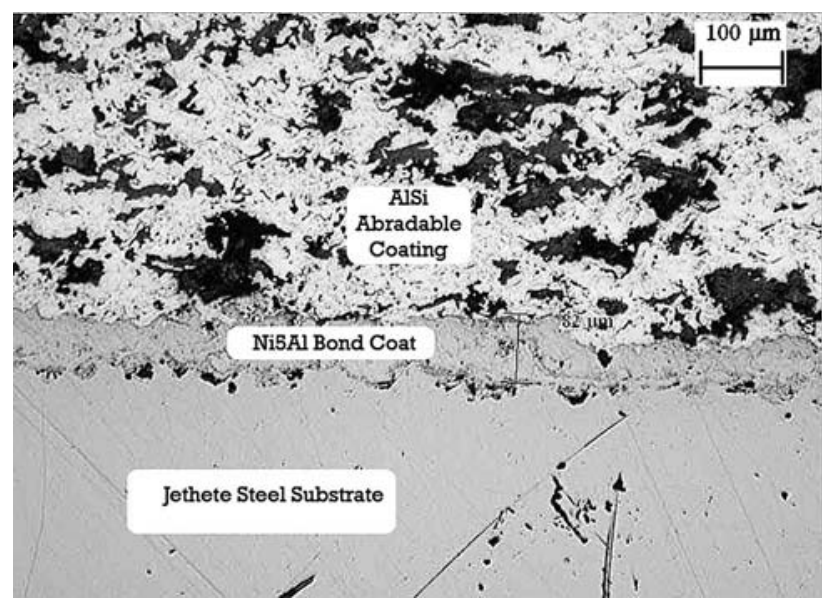

Fig. 2 Micrograph displaying substrate-bond coat-coating system 
for a relatively thin layer. Also, failure of sprayed parts normally occurs within the abradable coating or along the bond coat/abradable coating interface, not within the bond coat.

Tsui and Clyne's model used a quenching stress value based on coating deposit impacting upon substrate. With the bond coat incorporated into the modified model a quenching stress for bond coat impacting upon substrate material was used for calculations in the bond coat layer, and the quenching stress for coating impacting upon bond coat material was used for calculations in the abradable coating layers. Although Tsui and Clyne (Ref 10) used a measured value for the quenching stress (Ref 12), which is generally much lower than calculated values. The reason for this is that various stress relaxation mechanisms operate during the quenching of splats, the simulation of which would be very difficult numerically. The initial calculations (i.e. normal force, curvature change, composite beam stiffness, and the neutral axis position) used to determine the stresses due to coefficient of thermal expansion (CTE) mismatch consider the composite beam with two layers; substrate and abradable coating, i.e. bond coat is considered to be coating material. The calculation to determine the stress due to CTE mismatch during cooling within the bond coat layer uses the biaxial modulus for bond coat material.

The beam configuration for the modified model is shown in Fig. 3.

\section{Model Construction}

Tsui and Clyne's model was implemented for use with abradable seal coatings in Microsoft Excel. This environment was selected for greater visibility of all stages within the formulation chain particularly when performing the sensitivity study. The coating deposition was discretized into 10 layers for cumulative analysis. The first discretized layer consisted of bond coat material, as the thickness of the bond coat is typically $\sim 100 \mu \mathrm{m}$ and the total thickness of deposit for the example case is $0.001 \mathrm{~m}$ or $1000 \mu \mathrm{m}$. Therefore, [1000 $\mu \mathrm{m} / 10$ layers] equates to a layer thickness of $100 \mu \mathrm{m}$. The nine remaining layers are composed of coating material.

The input variables/material properties required by the model are outlined in Table 1.

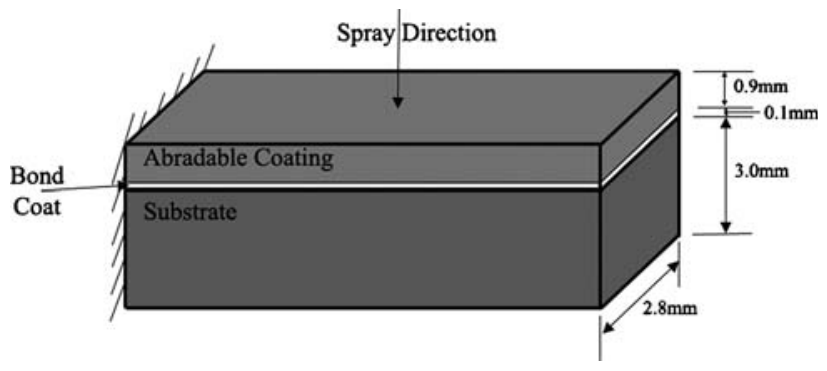

Fig. 3 Modified model beam configuration
$\Delta T_{\text {dep }}$ is calculated from:

$\Delta T_{\text {dep }}=T_{\mathrm{d}}-T_{\mathrm{s}}$

where $T_{\mathrm{d}}$ is the deposition temperature and $T_{\mathrm{s}}$ the substrate temperature.

$\Delta T_{\text {cool }}$ is calculated from:

$\Delta T_{\text {cool }}=T_{\mathrm{d}}-T_{\mathrm{RT}}$

where $T_{\mathrm{RT}}$ is the room temperature.

The biaxial moduli, $E^{\prime}$, are calculated using the modulus, $E$, and Poisson's ratio, $v$, values for the materials:

$E^{\prime}=\frac{E}{(1-v)}$

The biaxial modulus is used because an equal biaxial stress state is assumed $\left(\sigma_{x}=\sigma_{z}\right)$, with negligible through thickness stress $\left(\sigma_{y}=0\right)$.

From these input variables and initial calculations the model is defined, calculating the misfit strain of depositing bond coat material onto the substrate, $\Delta \varepsilon_{\mathrm{b}}$,

$\Delta \varepsilon_{\mathrm{b}}=\left(\alpha_{\mathrm{b}}-\alpha_{\mathrm{s}}\right) \Delta T_{\mathrm{dep}}$

where $\alpha_{\mathrm{b}}$ is the bond coat coefficient of thermal expansion and $\alpha_{\mathrm{s}}$ the substrate coefficient of thermal expansion.

Table 1 Input variable/material properties

\begin{tabular}{|c|c|c|}
\hline Symbol & Model input & Value \\
\hline$E_{\mathrm{d}}, \mathrm{Nm}^{-2}$ & Deposit modulus & $8.80 \mathrm{E}+09$ \\
\hline$E_{\mathrm{s}}, \mathrm{Nm}^{-2}$ & Bond coat modulus (a) & $3.00 \mathrm{E}+10$ \\
\hline$E_{\mathrm{s}}, \mathrm{Nm}^{-2}$ & Substrate modulus & $2.09 \mathrm{E}+11$ \\
\hline$\alpha_{\mathrm{d}}, \mathrm{K}^{-1}$ & $\begin{array}{l}\text { Deposit coefficient of thermal } \\
\text { expansion at room temperature } \\
\text { (CTE) }\end{array}$ & $2.60 \mathrm{E}-05$ \\
\hline$\alpha_{\mathrm{d}}, \mathrm{K}^{-1}$ & $\begin{array}{l}\text { Deposit coefficient of thermal } \\
\text { expansion at } \sim 569^{\circ} \mathrm{C}(\mathrm{CTE}) \text { (b) }\end{array}$ & $3.20 \mathrm{E}-05$ \\
\hline$\alpha_{\mathrm{b}}, \mathrm{K}^{-1}$ & Bond coat CTE at room temperature & $1.05 \mathrm{E}-05$ \\
\hline$\alpha_{\mathrm{b}}, \mathrm{K}^{-1}$ & Bond coat $\mathrm{CTE}$ at $\sim 569^{\circ} \mathrm{C}$ & $1.50 \mathrm{E}-05$ \\
\hline$\alpha_{\mathrm{s}}, \mathrm{K}^{-1}$ & Substrate CTE at room temperature & $9.82 \mathrm{E}-06$ \\
\hline$\alpha_{\mathrm{S}}, \mathrm{K}^{-1}$ & Substrate CTE at $\sim 569^{\circ} \mathrm{C}$ & $1.19 \mathrm{E}-05$ \\
\hline$h, \mathrm{~m}$ & Thickness of deposit & 0.001 \\
\hline$H, \mathrm{~m}$ & Thickness of substrate & 0.003 \\
\hline$b, \mathrm{~m}$ & Width of specimen & 0.028 \\
\hline$w, \mathrm{~m}$ & Layer thickness & 0.0001 \\
\hline$T_{\mathrm{d}},{ }^{\circ} \mathrm{C}$ & Deposition temperature (c) & 569 \\
\hline$T_{\mathrm{RT}},{ }^{\circ} \mathrm{C}$ & Room temperature & 20 \\
\hline$T_{\mathrm{s}},{ }^{\circ} \mathrm{C}$ & Substrate temperature & 150 \\
\hline$\Delta T_{\mathrm{dep}},{ }^{\circ} \mathrm{C}$ & Deposition temperature change & 419 \\
\hline$\Delta T_{\text {cool }},{ }^{\circ} \mathrm{C}$ & Cooling temperature change & 549 \\
\hline$n$ & Number of layers & 10 \\
\hline$v_{\mathrm{d}}$ & Deposit Poisson's ratio (d) & 0.22 \\
\hline$v_{\mathrm{b}}$ & Bond coat Poisson's ratio (e) & 0.312 \\
\hline$v_{\mathrm{S}}$ & Substrate Poisson's ratio & 0.296 \\
\hline $\begin{array}{l}\text { Biaxial modulus } \\
E_{\mathrm{d}}^{\prime}, \mathrm{Nm}^{-2}\end{array}$ & Biaxial modulus of deposit & $1.01 \mathrm{E}+10$ \\
\hline$E_{\mathrm{b}}^{\prime}, \mathrm{Nm}^{-2}$ & Biaxial modulus of bond coat (a) & $4.00 \mathrm{E}+10$ \\
\hline$E_{\mathrm{s}}^{\prime}, \mathrm{Nm}^{-2}$ & Biaxial modulus of substrate & $2.97 \mathrm{E}+11$ \\
\hline
\end{tabular}

(a) Estimate of bond coat modulus and biaxial modulus. Source: Ref 13

(b) Estimate of coating CTE at deposition temperature

(c) Estimate of deposition temperature utilizing solidus for $\mathrm{Al} 8 \% \mathrm{Si}$

(d) Estimate of deposit Poisson's ratio. Source: Ref 14

(e) Estimate of bond coat Poisson's ratio: [0.95*0.31]+ $[0.05 * 0.35]=[0.2945+0.0175]=0.312$ 
Misfit strain of depositing coating material onto bond coat, $\Delta \varepsilon_{\mathrm{d}}$,

$\Delta \varepsilon_{\mathrm{d}}=\left(\alpha_{\mathrm{d}}-\alpha_{\mathrm{b}}\right) \Delta T_{\text {dep }}$

where $\alpha_{\mathrm{d}}$ is the deposit coefficient of thermal expansion.

The quenching stress of depositing bond coat material onto the substrate, $\sigma_{\mathrm{qb}}$,

$\sigma_{\mathrm{qb}}=\Delta \varepsilon_{\mathrm{b}} \cdot E_{\mathrm{b}}$

where $E_{\mathrm{b}}$ is the bond coat modulus.

The quenching stress of depositing coating material onto bond coat, $\sigma_{\mathrm{qd}}$,

$\sigma_{\mathrm{qd}}=\Delta \varepsilon_{\mathrm{d}} \cdot E_{\mathrm{d}}$

where $E_{\mathrm{d}}$ is the deposit modulus.

\section{Deposition Stress}

The model initially considered only the first layer of sprayed deposit, which for this scenario consists of bond coat material. The tensile force acting upon the bond coat deposit and the equal but opposite compressive force acting upon the substrate were calculated for this initial layer. These equal but opposite forces generate a bending moment in the composite beam. The neutral axis position (the weighted center, measured from the interface) within the composite beam were also calculated, along with the composite beam stiffness, the curvature of the beam, the component of stress on the bottom and top of the substrate and at the midpoint of the deposited layer. For the first deposited layer, the material properties of the bond coat and substrate material were used.

The model considered each successive sprayed layer separately, but cumulatively. Therefore, the force, bending moment, neutral axis position, stiffness, curvature and substrate stress components at the bottom and top face and the midpoint stress of the current layer were calculated progressively as each layer is sprayed onto the previous layers.

Layers 2 to 10 consisted of abradable coating material, and therefore the material properties for this material were used in the calculations.

\section{Differential Thermal Contraction Cooling Stresses}

The initial calculations to determine the stresses due to coefficient of thermal expansivity mismatch consider the composite beam as a whole during cooling to room temperature. The mismatch strain was calculated using the cooling temperature gradient:

$\Delta \varepsilon=-\Delta T_{\text {cool }}\left(\alpha_{\mathrm{s}}-\alpha_{\mathrm{d}}\right)$

where $\Delta \varepsilon$ is the misfit strain and $\Delta T_{\text {cool }}$ the cooling temperature change.
This misfit strain imposes equal but opposite forces upon the deposit and substrate, which in turn generates an unbalanced moment, creating a curvature change in the composite beam. These are calculated with the equations outlined in Tsui and Clyne's (Ref 10) paper, as are the composite beam stiffness, the neutral axis position relative to the interface, and the stresses at the bottom and top of the substrate.

The stress due to differential thermal contraction during cooling through the deposit is calculated at the midpoint of each layer. The first layer (i.e. the bond coat layer) uses $E_{\mathrm{b}}^{\prime}$ in the calculation, whereas for the remaining layers (i.e. abradable coating layers), $E_{\mathrm{d}}^{\prime}$ is used.

\section{Model Results}

The model was implemented based on a $3 \mathrm{~mm}$ thick Jethete M152 (RR EAK) steel substrate, $0.1 \mathrm{~mm}$ $(100 \mu \mathrm{m})$ thick Ni5Al (Metco 450) bond coat, and $0.9 \mathrm{~mm}$ thick AlSi (Metco 320) abradable coating, and input variables/materials properties given in Table 1.

The following stress distribution was predicted (shown in Fig. 4).

Figure 4 plots the predicted net thermal spraying stresses at different points through the thickness of the part. Zero through thickness is the interface between the substrate and the bond coat. The substrate spans the through thickness region 0 to $-3 \mathrm{~mm}$, the bond coat spans 0 to $0.1 \mathrm{~mm}$, and the coating spans 0.1 to $1 \mathrm{~mm}$.

The stress on the back surface of the substrate is a tensile stress of $151.21 \mathrm{MPa}$ and on the top surface of the substrate is a compressive stress of $-251.54 \mathrm{MPa}$. The stress at the midpoint of the bond coat layer is a tensile stress of $115.64 \mathrm{MPa}$. The predicted stress in the coating increases slightly from $152.82 \mathrm{MPa}$ at the midpoint of layer two (adjacent to bond coat) to $153.42 \mathrm{MPa}$ at the midpoint of layer ten (the top surface of the coating). This is due to the fact that the deposition of further coating layers reduces the component of tensile stress in the preceding layers (Ref 10). Although the misfit strain is the same for each incremental layer of the deposit, the thickness of the 'substrate' (substrate and deposited coating) on which the coating is deposited is gradually increasing. This increasing 'substrate' thickness results in a greater tensile force within the coating layer.

The tensile residual stress in the deposited coating and bond coat can be attributed to the two sources: deposition stresses and differential thermal contraction cooling stresses. The deposition stress, sometimes referred to as 'quenching stress' (Ref 12), is developed when the deposited material (splat) at high temperature impacts upon the surface of the substrate, which is at a lower temperature, and cools very rapidly. The splat cools and contracts, but the level of contraction is constrained by the underlying substrate material. A tensile quenching stress is therefore introduced into the coating, as shown in Fig. 5. In practice, the substrate temperature would increase as splats at high temperature impact upon its surface, 


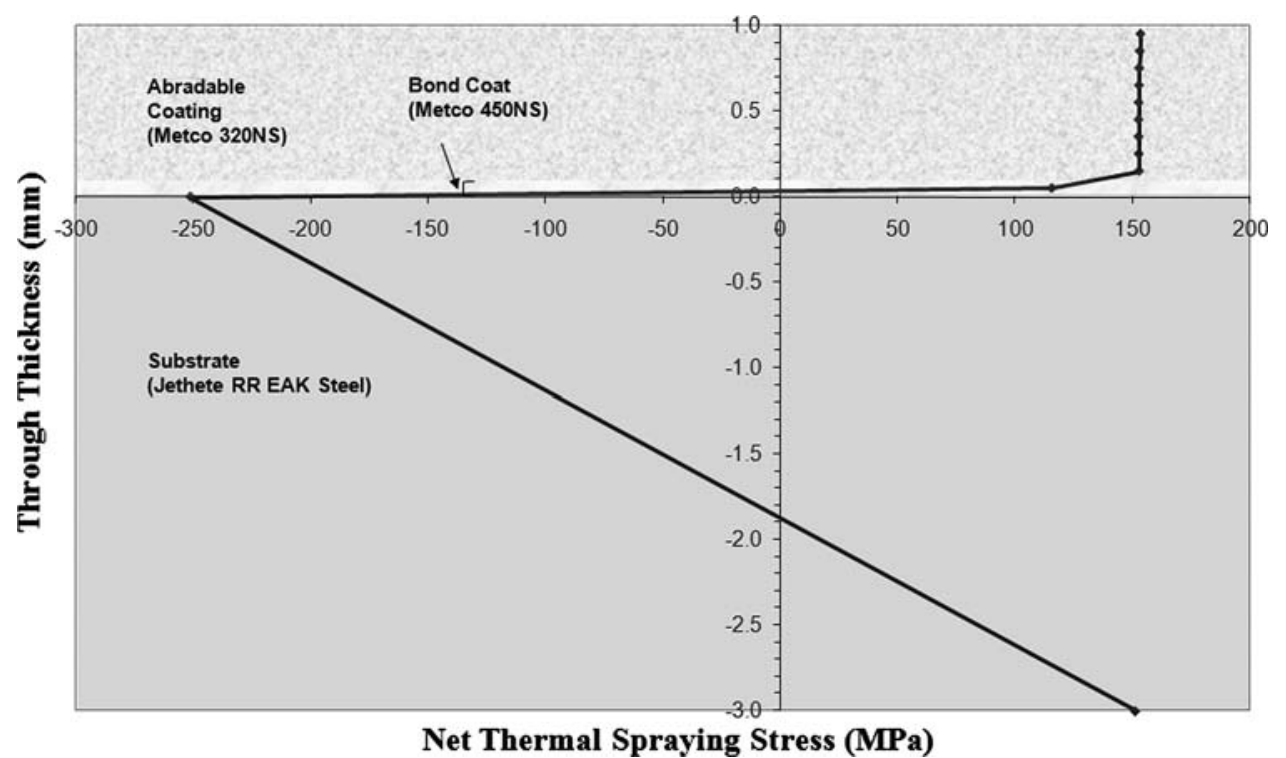

Fig. 4 Net thermal spraying stress through substrate, bond coat and coating

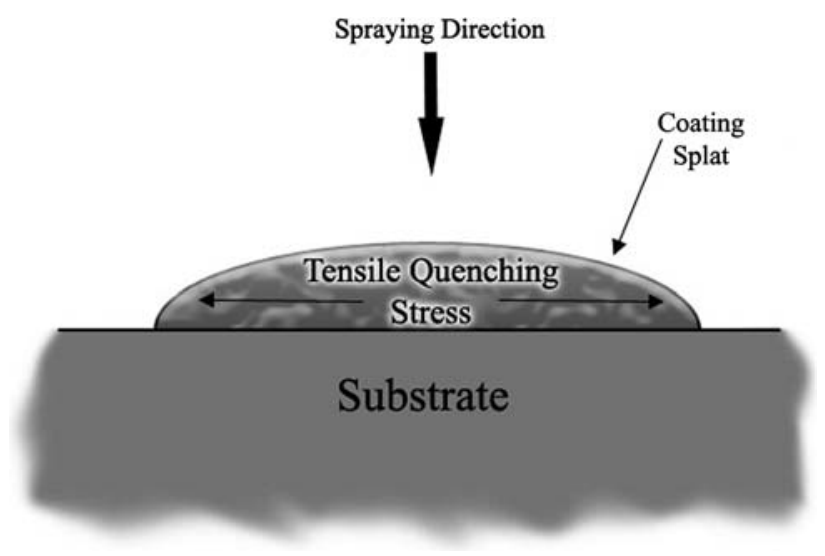

Fig. 5 Deposition residual stress

therefore causing the substrate to expand in opposition to the contracting splat layer.

The cooling stress introduced as the composite beam cools to room temperature is purely attributable to the coefficient of thermal expansion mismatch in adjacent materials. Whether the induced cooling stress in the deposit is compressive or tensile depends upon the relative values of the materials' CTE. If, during cooling, the deposited material contracts more than the substrate (i.e. $\alpha_{\mathrm{bc}}>\alpha_{\mathrm{s}}$ or $\alpha_{\mathrm{d}}>\alpha_{\mathrm{bc}}$ ), a tensile stress is produced in the deposited material, as shown in Fig. 6.

If the CTE for the materials is equal, then no cooling stresses will form in the composite. However, if the CTE for the substrate material is greater than that of the deposited material (i.e. $\alpha_{\mathrm{s}}>\alpha_{\mathrm{bc}}$ or $\alpha_{\mathrm{bc}}>\alpha_{\mathrm{d}}$ ), the stress in the deposited material due to cooling will be compressive. It should be noted though that the overall residual stress may still be tensile despite the compressive cooling stress if the deposition residual tensile stress is greater in

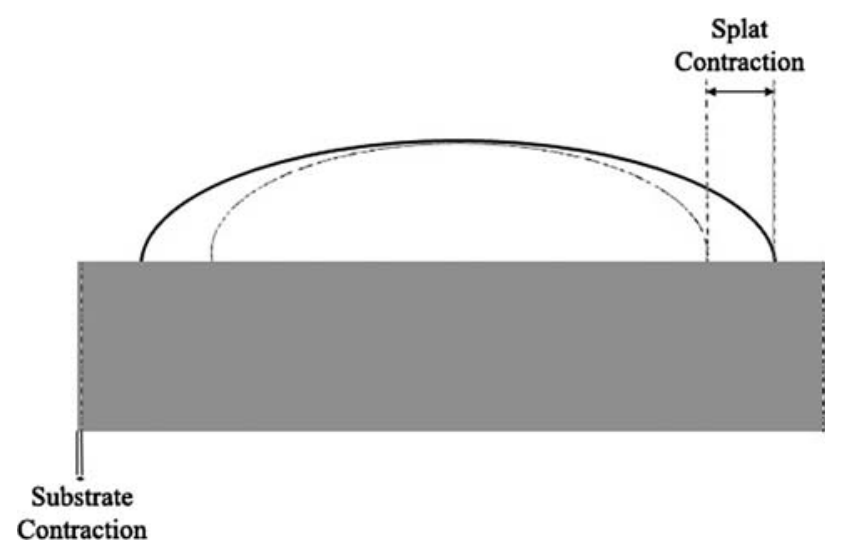

Fig. 6 Cooling residual stress when $\alpha_{b c}>\alpha_{s}$ or $\alpha_{d}>\alpha_{b c}$

magnitude than the compressive cooling stress. This implies that with the correct selection of materials, a composite sprayed specimen with zero residual stress is possible, yet this is unlikely for the application of abradable seals.

The strain in the substrate during deposition and cooling is greater than that of the bond coat and coating; this is driven by the large modulus mismatch. The bond coat and the substrate are rigidly joined at the interface, resulting in a tensile stress in the bond coat and coating, and a large compressive stress at the top surface of the substrate as each component attempts to deform by an equal amount. This is represented by an upwards curvature in the composite beam.

\section{Sensitivity Study of Input Parameters}

A sensitivity study is a valuable tool when investigating the lifecycle stresses within an abradable coating, and 
identification of the performance drivers to the mechanical integrity of the coating. The sensitivity of the output response (stress distribution) to variation of the input parameters was investigated. The following plots highlight the relationships between selected input parameters and the net thermal spraying residual stress (NTSRS) through the substrate, bond coat, and coating.

Figure 7 shows the effect increasing the deposit modulus has on the NTSRS at the different points through the thickness of the coating. [-3.00] equates to the bottom surface of the substrate, [0.00] is the top face of the substrate, [0.05] is the midpoint of the bond coat layer, [0.15] is the midpoint of the first abradable coating layer, and [0.95] is the midpoint of the last abradable coating layer. Despite the difficulty in envisaging the potential operational envelope for coating modulus values, Fig. 7 suggests that decreasing the deposit modulus decreases the NTSRS significantly in all sections of the sprayed beam. The quenching stress constitutes between 38 and $40 \%$ of the total calculated residual stress at the midpoint of the coating when varying the modulus.

As with Fig. 7, applying a potential practical envelope to bond coat modulus values is difficult due to a lack of data for such materials, therefore a large range was applied. From Fig. 8 it is clear that for all points except in the bond coat itself, the NTSRS is highly insensitive to changes in the bond coat modulus. The practical modulus of this family of sprayed materials is unlikely to be higher than $100 \mathrm{GPa}$. Therefore, over the range 5-100 GPa, the NTSRS in the bond coat increased from 98.89 to

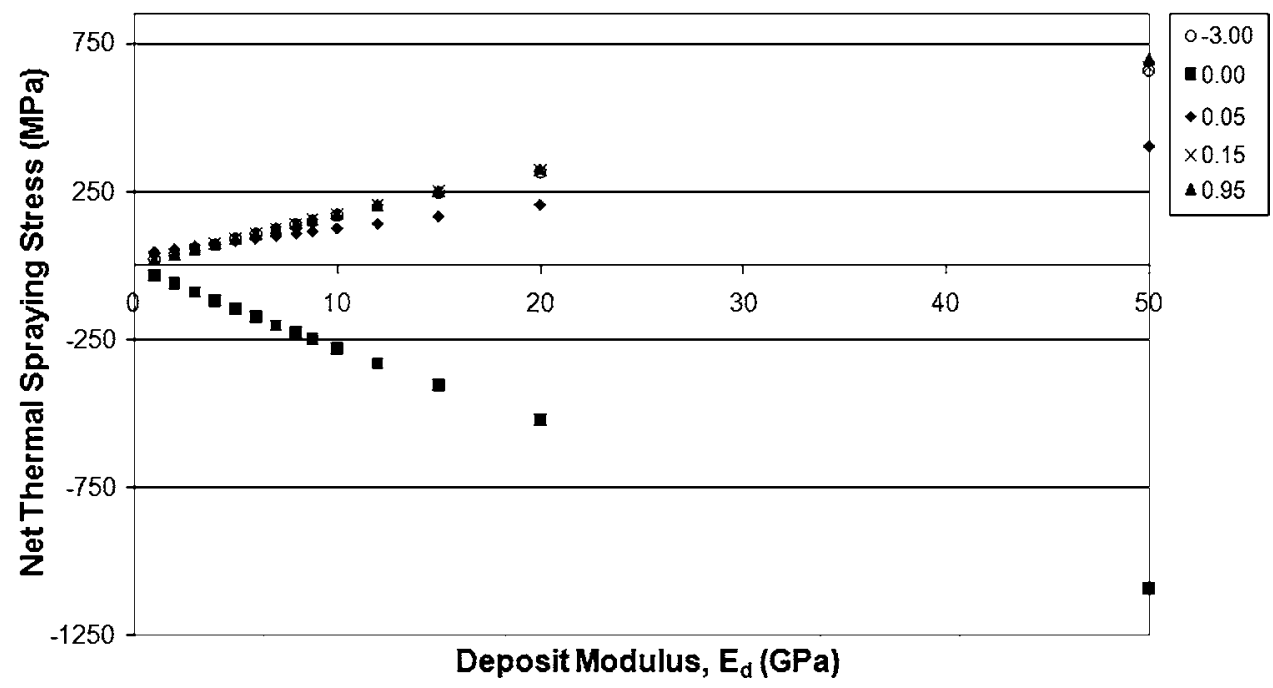

Fig. 7 Sensitivity of NTSRS to deposit (abradable) modulus

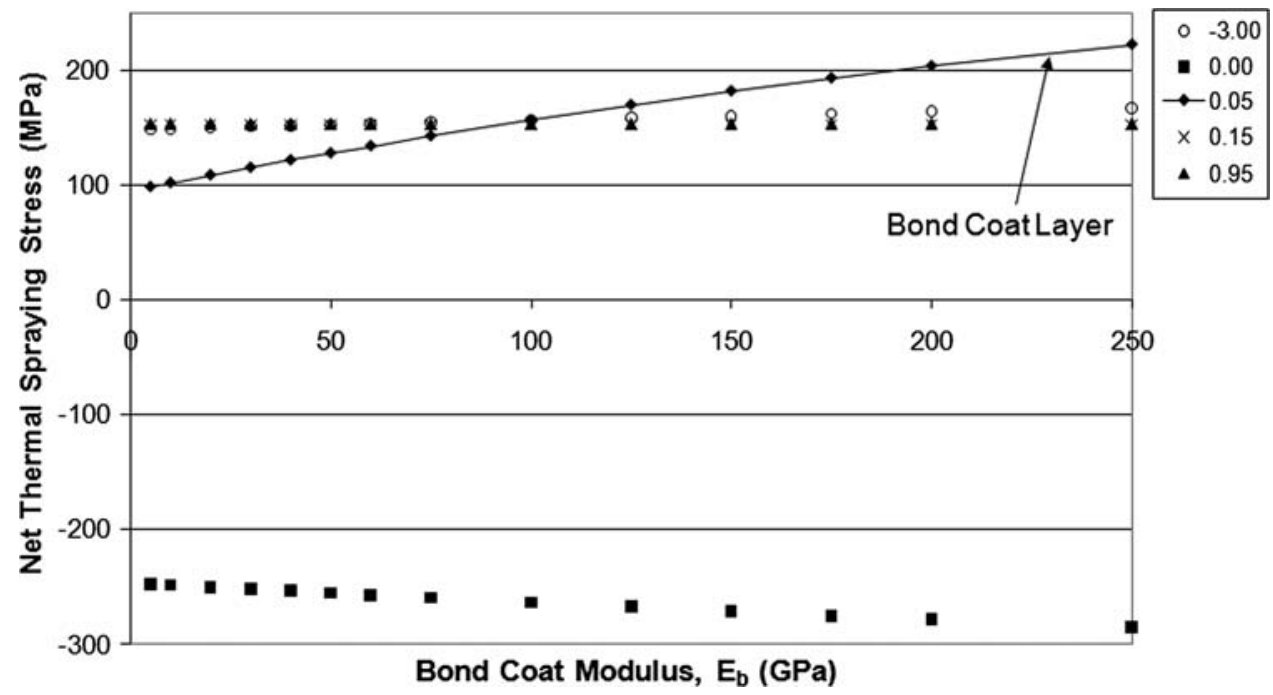

Fig. 8 Sensitivity of NTSRS to bond coat modulus 
157.10 MPa, which equates to a $58.9 \%$ (58.2 $\mathrm{MPa})$ increase in NTSRS when bond coat modulus is increased over its potential operational range. It is therefore suggested that the NTSRS in the bond coat is moderately sensitive to variation in bond coat modulus. The quenching stress constitutes $39 \%$ of the total calculated residual stress at the midpoint of the coating when varying the bond coat modulus.

A sensible practical envelope could be applied to Fig. 9 for substrate modulus. A range of 75-250 $\mathrm{MPa}$ was used, which is rather generous, but encompasses a wide range of potential structural materials. Increasing the substrate modulus over this range generates an increase in the bond coat NTSRS of $47.6 \%(38.5 \mathrm{MPa})$, an increase of $12.1 \%$ $(16.5 \mathrm{MPa})$ in the tensile NTSRS at the bottom surface of the substrate, and $12.1 \%(27.5 \mathrm{MPa})$ in the compressive
NTSRS at the top surface of the substrate, and also an increase of $12.2 \%(16.7 \mathrm{MPa})$ at the center of the abradable deposit. It can therefore be concluded that the NTSRS in the substrate and abradable coating is relatively insensitive to changes in the substrate modulus, but the bond coat layer is moderately sensitive to substrate modulus variation. The quenching stress constitutes between 39 and $41 \%$ of the total calculated residual stress at the midpoint of the coating when varying the substrate modulus.

A practical envelope of between 0.6 and $2.0 \mathrm{~mm}$ was applied for investigating coating thickness variation and its effects on the NTSRS. Figure 10 shows that over this range the tensile NTSRS in the substrate bottom surface increased by a factor of $4.4(278.9 \mathrm{MPa})$, and the compressive NTSRS at the substrate top surface increased by a

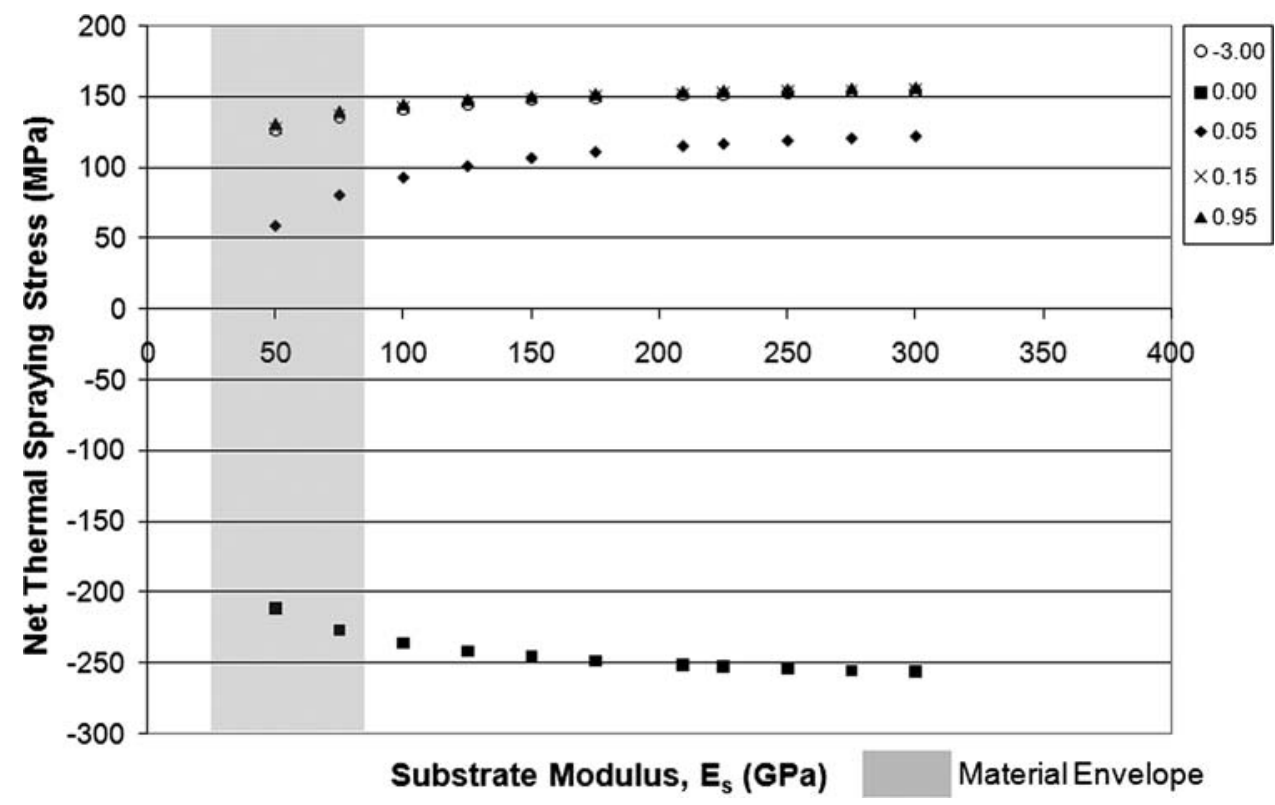

Fig. 9 Sensitivity of NTSRS to substrate modulus

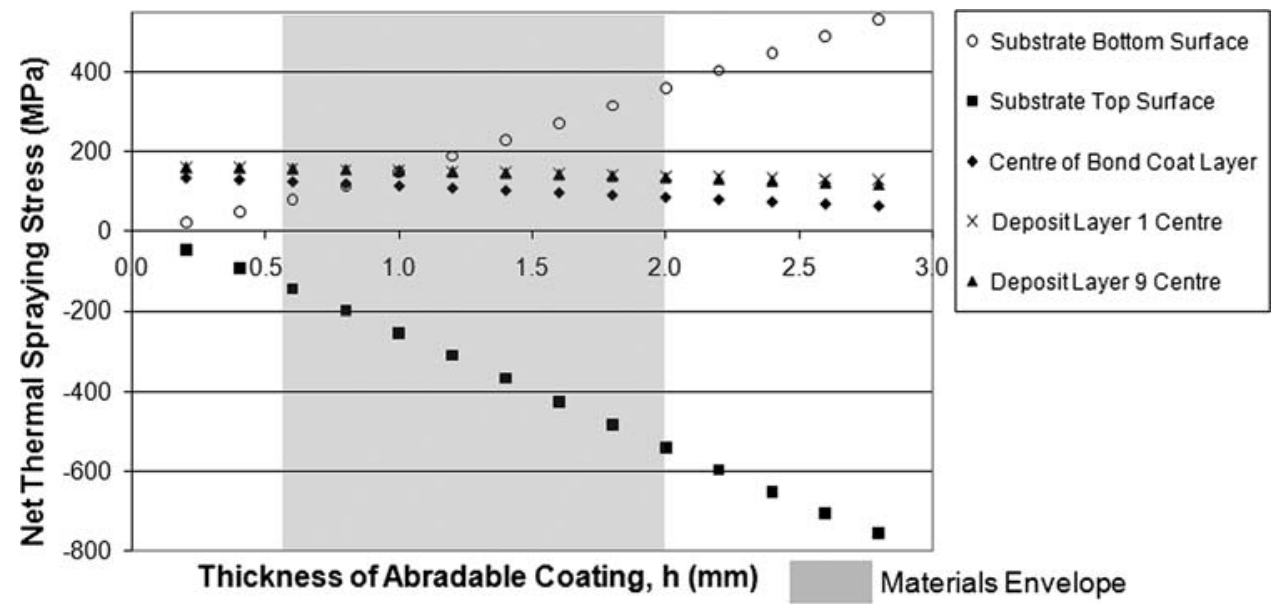

Fig. 10 Sensitivity of NTSRS to abradable coating thickness 
factor of $3.8(396.0 \mathrm{MPa})$. The NTSRS in the bond coat decreased by $31.1 \%$ (39.2 MPa), and in the center of the abradable deposit it decreased by $14.0 \%$ (22.1 MPa). It was concluded that the NTSRS values in the substrate are highly sensitive to deposit thickness, and the bond coat NTSRS is moderately sensitive to deposit thickness, whereas the NTSRS in the abradable coating is relatively insensitive to varying coating thickness. The quenching stress constitutes between 39 and $40 \%$ of the total calculated residual stress at the midpoint of the coating when varying the coating thickness.

Defining a reasonable operational envelope for substrate thickness was not possible at this time. However, it can be seen from Fig. 11 that over the range studied, the NTSRS in the substrate in highly sensitive to changes in the substrate thickness, and the NTSRS in the bond coat increases by $105.62 \mathrm{MPa}$ over the substrate thickness range $0.5-6.5 \mathrm{~mm}$. The NTSRS in the center of the abradable deposit also increases, by $100.66 \mathrm{MPa}$. The quenching stress constitutes between 39 and $42 \%$ of the total calculated residual stress at the midpoint of the coating when varying the substrate thickness.

The operating envelope selected for the initial substrate temperature begins at room temperature $\left(20^{\circ} \mathrm{C}\right)$ and extends up to $600{ }^{\circ} \mathrm{C}$. This operating envelope encompasses a large temperature range to reflect the studies in varying substrate temperature (Ref 15-17). As shown in Fig. 12, the tensile NTSRS for the bottom surface of the substrate decreases by $47.9 \%(81.08 \mathrm{MPa})$ over the substrate temperature range $20-600{ }^{\circ} \mathrm{C}$, and the compressive NTSRS for the top surface of the substrate decreases by $47.9 \%$ (134.32 MPa). The tensile NTSRS in the bond coat decreases by $38.4 \%(48.6 \mathrm{MPa})$, and decreases by $48.5 \%$ $(83.07 \mathrm{MPa})$ in the center of the abradable coating. These results can be explained by the fact the $\Delta T$ value is decreasing as the substrate temperature is increased.

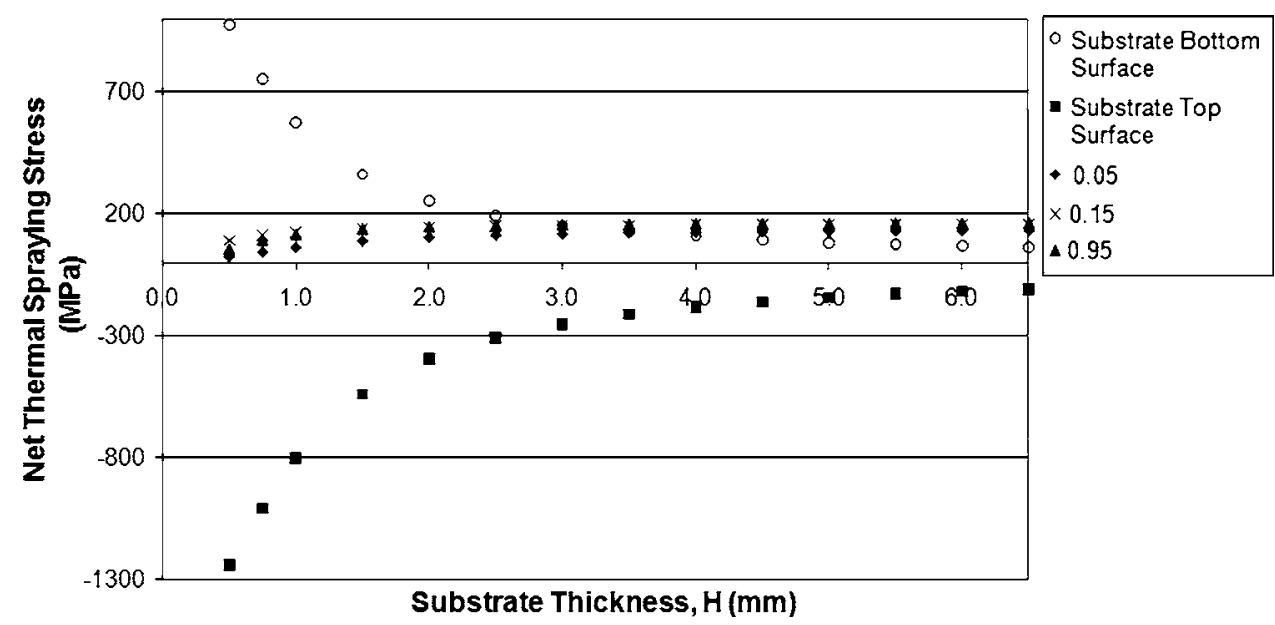

Fig. 11 Sensitivity of NTSRS to substrate thickness

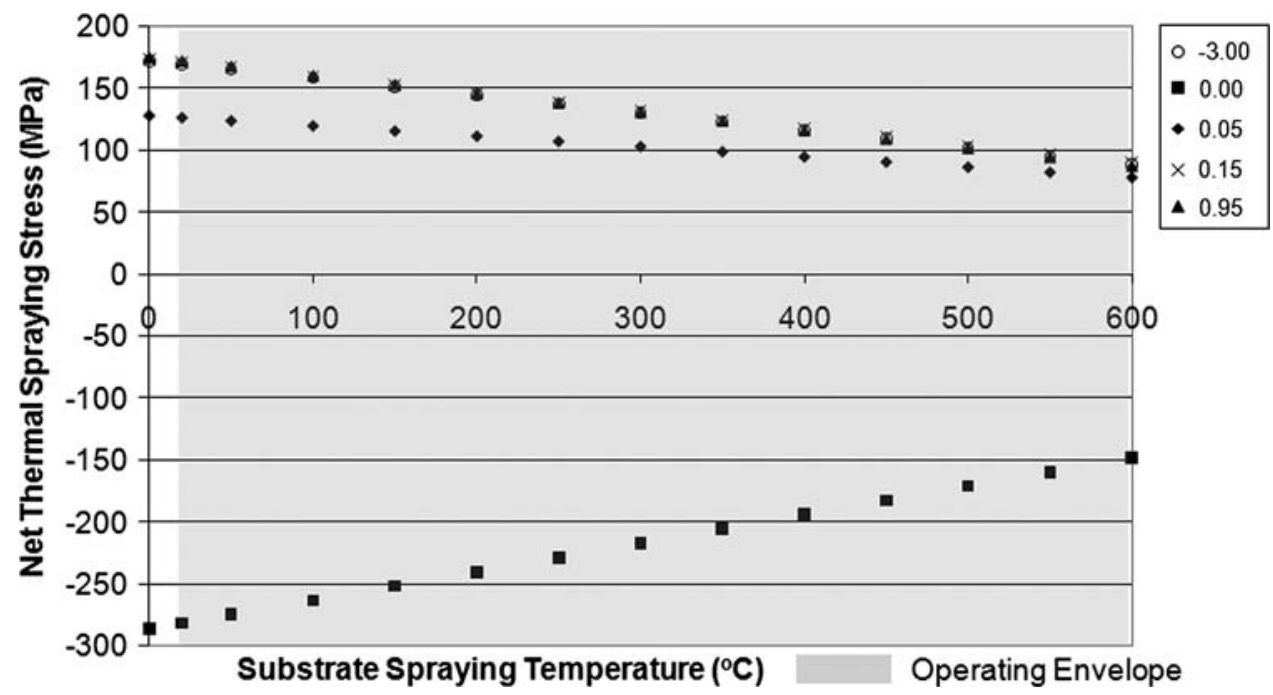

Fig. 12 Sensitivity of NTSRS to initial substrate temperature 
Therefore, the driving force for the generation of quenching stresses is minimized. The quenching stress constitutes between $5 \%$ (at $600{ }^{\circ} \mathrm{C}$ ) and $46 \%$ (at $20{ }^{\circ} \mathrm{C}$ ) of the total calculated residual stress at the midpoint of the coating when varying the substrate temperature.

The sensitivity of the NTSRS to varying Poisson's ratio was also investigated. The Poisson's ratio for each of the three constituents of the system (abradable coating, bond coat, and substrate) was varied between 0.2 and 0.3 . Varying the Poisson's ratio over this range yielded very little variation in the calculated NTSRS at all points in the system; therefore the NTSRS is insensitive to Poisson's ratio.

\section{Discussion}

Table 2 categorizes the different input parameters and materials properties that affect the residual stresses at the bottom and top surfaces of the substrate, the midpoint of the bond coat and abradable coating.

Of the input parameters investigated in the sensitivity study, substrate thickness has a greater relative effect on the NTSRS over the studied range for the bottom and top surfaces of the substrate than any of the other parameters. The NTSRS at the midpoint of the bond coat and abradable coating are also relatively sensitive to changes in the substrate thickness. The calculated NTSRS at the substrate top and bottom surfaces is highly sensitive to changes in the deposit thickness, whereas the NTSRS in the bond coat and abradable coating exhibit a small amount of sensitivity.

Also, the abradable deposit modulus has a great effect on the NTSRS at the midpoint of the bond coat and abradable coating, and a large effect on the NTSRS at the substrate surfaces. The bond coat modulus appears to only significantly affect the NTSRS in the bond coat itself. Changes to the substrate modulus had limited effect on the calculated NTSRS at all measured points.

The Poisson's ratios for all materials have relatively little effect on the respective NTSRS at all defined points within the calculation layers. The initial substrate temperature has a large effect on the NTSRS at the midpoint of the abradable coating, but less of an effect within the substrate and bond coat.

The model assumes elasticity of all materials, which leads to inaccuracies in stress calculation when the model returns relatively high stress values within all materials. The situation described by the model is one of an ideal situation where all layers are aligned in the longitudinal direction, whereas in reality the splats are not continuous; there may be pores and cracks between the splats (Ref 18). The model also does not consider heat transfer between and within the separate bodies. Incorporation of the temperature distribution with time would provide greater accuracy when calculating stresses.

The effects of varying all of the spray parameters are not investigated. Many spray parameter settings are taken to be inherent within the materials properties for the abradable coating and bond coat. In practice, after the sprayed coating has cooled, the top surface is machined to achieve a better surface finish. This would mean the internal stresses redistribute as a layer of stressed coating material is machined off.

The sensitivity study was not extended to the materials' coefficients of thermal expansion because the values were temperature dependent. Therefore, it would have been possible to vary the CTE for any of the three parts at deposition temperature, but giving a corresponding value for the CTE at any other temperature would have been impossible without knowing the specific material. When devising a new abradable coating material based on the results of the sensitivity study, changing one material property will likely be coupled with changes to other materials properties. The impact of these on the residual stress should also be considered.

The quenching stresses used in this modified model were calculated using Eq 6 and 7. For each of the sensitivity studies, the quenching stress constituted approximately $40 \%$ of the total calculated thermal residual stress at the midpoint of the coating, except for the investigation of substrate temperature, where matching of the substrate temperature to a value nearer the sprayed coating temperature produces a reduced quenching stress $(5 \%$ of the NTSRS). Equations 6 and 7 would likely lead to

Table 2 Sensitivity study results summary

\begin{tabular}{|c|c|c|c|c|c|c|c|c|}
\hline & \multicolumn{4}{|c|}{ Change in NTSRS over studied range, MPa } & \multicolumn{4}{|c|}{$\begin{array}{l}\text { Relative sensitivity of NTSRS (1 = highly sensitive, } \\
\qquad=\text { insensitive })\end{array}$} \\
\hline & $\begin{array}{c}\text { Bottom } \\
\text { surface of } \\
\text { substrate }\end{array}$ & $\begin{array}{l}\text { Top surface } \\
\text { of substrate }\end{array}$ & $\begin{array}{l}\text { Midpoint } \\
\text { of bond } \\
\text { coat }\end{array}$ & $\begin{array}{c}\text { Midpoint } \\
\text { of abradable } \\
\text { deposit }\end{array}$ & $\begin{array}{c}\text { Bottom } \\
\text { surface of } \\
\text { substrate }\end{array}$ & $\begin{array}{c}\text { Top } \\
\text { surface of } \\
\text { substrate }\end{array}$ & $\begin{array}{l}\text { Midpoint } \\
\text { of bond } \\
\text { coat }\end{array}$ & $\begin{array}{c}\text { Midpoint } \\
\text { of abradable } \\
\text { deposit }\end{array}$ \\
\hline Deposit modulus & 277.31 & -459.56 & 148.42 & 285.15 & 3 & 2 & 1 & 1 \\
\hline Bond coat modulus & 8.06 & -15.84 & 58.21 & 0.00 & 7 & 7 & 3 & 7 \\
\hline Substrate modulus & 16.49 & -27.52 & 38.46 & 16.73 & 6 & 6 & 6 & 4 \\
\hline Deposit thickness & 278.93 & -396.06 & -39.21 & -22.12 & 2 & 3 & 5 & 6 \\
\hline Substrate thickness & -507.91 & 686.21 & 67.80 & 44.35 & 1 & 1 & 2 & 3 \\
\hline Deposit Poisson's ratio & 24.44 & -40.77 & 23.31 & 24.37 & 5 & 5 & 7 & 5 \\
\hline Bond coat Poisson's ratio & -0.02 & 0.03 & -5.46 & 0.00 & 9 & 9 & 9 & 7 \\
\hline Substrate Poisson's ratio & 2.67 & -4.45 & 6.26 & 2.71 & 8 & 8 & 8 & 6 \\
\hline Initial substrate temperature & 81.08 & -134.32 & 48.59 & 83.07 & 4 & 4 & 4 & 2 \\
\hline
\end{tabular}


overestimation of the actual quenching stresses as many stress relaxation mechanisms operate during the quenching of splats. Ideally, the quenching stress would be measured for each spray material impacting upon the relevant substrate, as outlined in Kuroda and Clyne (Ref 12). Therefore, taking the calculated NTSRS values from this current modified model in isolation has little value, but the relative effects of varying material properties and processing parameters have significant value when attempting to conceive a new material for application as an abradable seal.

\section{Conclusions}

Tsui and Clyne's analytical model for predicting progressively deposited coatings (Ref 10) was used, in conjunction with formulated bond coat layer inclusion modifications, to facilitate a sensitivity study of input parameters of the spraying process and material properties, and their effect on the predicted NTSRS.

Using processing parameters and materials properties based on a Jethete steel substrate, Ni5Al bond coat, and AlSi-hBN abradable coating system, the predicted thermal spraying residual stresses were tensile in the abradable coating and bond coat, compressive at the top surface of the substrate, and tensile at the bottom surface of the substrate.

Actual values for stresses cannot be taken from this study as this model does not currently take into account the stress relaxation mechanisms evident during quenching of sprayed splats, but their relative values can be used to determine the sensitivities.

It was found that the NTSRS at the bottom and top surfaces of the substrate is most sensitive to changes in substrate thickness, abradable deposit thickness, and deposit modulus.

The NTSRS at the midpoint of the bond coat is most sensitive to changes in the deposit modulus, substrate thickness, and bond coat modulus. The NTSRS at the midpoint of the abradable coating was found to be most sensitive to changes in the deposit modulus, initial substrate temperature, and substrate thickness.

This knowledge can be used in the future investigation and creation of new abradable materials with optimum stress profiles and greater mechanical integrity.

\section{Acknowledgments}

The data in this paper were generated in the MACE (Materials for Arduous Cycles and Emissions) project (TP/2/ET/6/I/10037), which forms part of the Technology Strategy Board Technology Programme. The author would like to acknowledge the technical contributions from colleagues based at Rolls Royce plc., in particular Chris Sellars, Sulzer Metco, and Cranfield University.

\section{References}

1. F. Ghasripoor, R. Schmid, and M. Dorfman, Abradables Improve Gas Turbine Efficiency, Mater. World, 1997, 5(6), p 328-330

2. R. Knight and R.W. Smith, Thermal Spray Forming of Materials, Powder Metal Technologies and Applications, ASM Handbook, Vol 7, P.W. Lee, Ed., ASM International, OH, 1998, p 408419

3. G.G. Stoney, The Tension of Metallic Films Deposited by Electrolysis, Proc. R. Soc. Lond. A, 1909, 82, p 172-175

4. S. Timoshenko, Analysis of Bi-Metal Thermostats, J. Opt. Soc. Am., 1925, 11(3), p 233-255

5. C.H. Hsueh and A.G. Evans, Residual Stresses and Cracking in Metal/Ceramic Systems for Microelectronics Package, J. Am. Ceram. Soc., 1985, 68(3), p 120-127

6. C.H. Hsueh, Modeling of Elastic Deformation of Multilayers Due to Residual Stresses and External Bending, J. Appl. Phys., 2002, 91(12), p 9652-9656

7. W.G. Mao, Y.C. Zhou, L. Yang, and X.H. Yu, Modeling of Residual Stresses Variation with Thermal Cycling in Thermal Barrier Coatings, Mech. Mater., 2006, 38(12), p 1118-1127

8. T.W. Clyne, Residual Stresses in Surface Coatings and Their Effects on Interfacial Debonding, Key Eng. Mater., 1996, 116, p 307-330

9. X.C. Zhang, B.S. Xu, H.D. Wang, and Y.X. Wu, An Analytical Model for Predicting Thermal Residual Stresses in Multilayer Coating Systems, Thin Solid Films, 2005, 488, p 274-282

10. Y.C. Tsui and T.W. Clyne, An Analytical Model for Predicting Residual Stresses in Progressively Deposited Coatings, Part 1: Planar Geometry, Thin Solid Films, 1997, 306, p 23-33

11. R.E. Johnston and W.J. Evans, Freestanding Abradable Coating Manufacture and Tensile Test Development, Surf. Coat. Technol., 2007, 202(4-7), p 725-729

12. S. Kuroda and T.W. Clyne, The Quenching Stress in Thermally Sprayed Coatings, Thin Solid Films, 1991, 200, p 49-66

13. S.H. Leigh, C.K. Lin, and C.C. Berndt, Elastic Response of Thermal Spray Deposits under Indentation Tests, J. Am. Ceram. Soc., 1997, 80(8), p 2093-2099

14. H.I. Faraoun, J.L. Seichapine, C. Coddet, H. Aourag, J. Zwick, N. Hopkins, D. Sporer, and M. Hertter, Modelling Route for Abradable Coatings, Surf. Coat. Technol., 2006, 200(22-23), p 6578-6582

15. X. Jiang, J. Matejicek, and S. Sampath, Substrate Temperature Effects on Splat Formation, Microstructure Development and Properties of Plasma Sprayed Coatings. Part I: Case Study for Partially Stabilized Zorconia, Mater. Sci. Eng. A, 1999, 272(1), p 181-188

16. X. Jiang, J. Matejicek, and S. Sampath, Substrate Temperature Effects on Splat Formation, Microstructure Development and Properties of Plasma Sprayed Coatings. Part II: Case Study for Molybdenum, Mater. Sci. Eng. A, 1999, 272(1), p 189-198

17. V. Teixeira, M. Andritschky, W. Fischer, H.P. Buchkremer, and D. Stöver, Analysis of Residual Stresses in Thermal Barrier Coatings, J. Mater. Process. Tech., 1999, 92-93, p 209-216

18. D. Wang and C.C. Berndt, Anisotropic Thermal Expansion Behaviour of Thermally Sprayed Coatings, Proceedings of 2nd Plasma-Technik-Symposium, Vol 2, S. Blum-Sandmeier, $\mathrm{H}$. Eschnauer, P. Huber, and A.R. Nicoll, Ed., 1991 (Lucerne, Switzerland), p 295-304 